THE INTERNATIONAL JOURNAL OF AVIATION PSYCHOLOGY, 16(1), 51-76

Copyright @ 2006, Lawrence Erlbaum Associates, Inc.

\title{
Pilot Navigation Errors on the Airport Surface: Identifying Contributing Factors and Mitigating Solutions
}

\author{
Becky L. Hooey \\ Monterey Technologies, Inc., at NASA Ames Research Center \\ Moffett Field, California \\ David C. Foyle \\ Human Factors Research and Technology Division \\ NASA Ames Research Center \\ Moffett Field, California
}

\begin{abstract}
A taxonomy of navigation errors (pilot deviations) during taxi operations was developed that defines 3 classes of errors: planning, decision, and execution errors. This taxonomy was applied to error data from 2 full-mission simulation studies (Hooey, Foyle, Andre, \& Parke, 2000; McCann et al., 1998) that included trials that replicated current-day operations and trials with advanced cockpit technologies including datalink, electronic moving maps (EMM), and head-up displays (HUDs). Pilots committed navigation errors on $17 \%$ of current-day operations trials (in low-visibility and night), distributed roughly equally across the 3 error classes. Each error class was associated with a unique set of contributing factors and mitigating solutions. Planning errors were mitigated by technologies that provided an unambiguous record of the clearance (datalink and the EMM, which possessed a text-based clearance). Decision errors were mitigated by technologies that provided both local and global awareness including information about the distance to and direction of the next turn, current ownship location, and a graphical depiction of the route (as provided by the EMM and HUD together). Execution er ror s were best mitigated by the HUD, which disambiguated the environment and depicted the cleared taxi route. Implications for technology design and integration are provided.
\end{abstract}

Correspondence should be sent to Becky L. Hooey, San Jose State University at NASA Ames Research Center, MS 262-4, Moffett Field, CA 94035. Email: bhooey@mail.arc.nasa.gov 
On the airport surface, navigation errors (i.e., failure to comply with the taxi clearance issued by air traffic control [ATC]) are often simply considered an inconvenience that increases time to taxi, fuel burn, and adversely affects airline on-time performance. However, although these navigation errors certainly slow airport operations, they are also a serious safety threat. In general, pilots that commit navigation errors either do not know where they are on the airport surface or have misunderstood where they are supposed to be. Either of these may lead a pilot to inadvertently taxi onto, or across, an active runway.

Runway incursions are defined as any occurrence on an airport runway involving an aircraft, vehicle, person, or object on the ground that creates a collision hazard or results in a loss of required separation with an aircraft taking off, landing, or intending to land (Federal Aviation Administration [FAA], 2002a). In recent years, the rate of runway incursions has risen to a level of sufficient concern that the FAA has developed a runway safety blueprint (FAA, 2002b) and conducted regional and national workshops to identify solutions to the increasing runway incursion problem. They report that from the years 1998 to 2001, there were 1,460 runway incursions at U.S. airports. In the blueprint, numerous suggestions were raised including procedural and operational changes, improvements to pavement markings and signage, and in-cockpit navigation technologies. One such FAA program, Safe Flight 21, has been established with the goal of providing pilots with cockpit-based tools to reliably increase their awareness of their position on the air port surface (FAA Safe Flight 21, 2002).

To devise, prioritize, implement, and predict the success of potential solutions it is imperative that we first better under stand the nature of the runway incursion problem. This article addresses the largest cause of the runway incursion problem: navigation errors attributed to pilot deviations. Pilot deviations accounted for 58\% of the runway incursions reported, operational errors (ATC) accounted for 23\%, and vehicle or pedestrian errors accounted for 19\% (FAA, 2002a). The goals of this article are to understand the factor s that contribute to pilot navigation errors, identify potential mitigating solutions that directly address the contributing factors, and provide empirical data to support the logical choice of technologies into the cockpit. To accomplish this, first a description of the taxi task as developed from pilot surveys, observation, and focus groups is provided. Based on this description, an error taxonomy is presented that classifies navigation errors into one of three error categories based on observable behaviors. Next, this taxonomy is applied to navigation errors that were observed in two full-mission surface operations simulations and causal factors of each class of error in the taxonomy are identified. In addition, cockpit navigation and communication technologies that were investigated in the full-mission simulations are examined for their effec- 
tiveness of mitigating each error class. The procedures and data within this article are derived from two-crew-member commercial aircraft operations, and focus solely on arrival taxi operations. Mitigating solutions, including procedural, operational, and technology solutions, are identified by considering the nature of each error class and the characteristics inherent in the technologies that were successful at reducing errors in each class.

\section{THE TAXI TASK}

Prior to exploring error causes and mitigating strategies, it is first necessary to understand the taxi task. To accomplish this, three main sources of information were used: (a) a large-scale study that surveyed more than 2,000 pilots about their problems with, and proposed solutions for, surface navigation and communications (Adam \& Kelley, 1996); (b) an observational study in which 35 commercial aircraft crews were observed during their regularly scheduled flights (Andre, 1995); and (c) a series of scenario-based focus groups in which 16 pilots and 8 air traffic controllers discussed problems with surface operations (Hooey et al., 1999). An analysis of these rich information sources revealed three high-level tasks that are required for successful navigation of a taxi route: plan the taxi route, make navigation decisions, and execute the decisions. Each is described next.

\section{Planning the Taxi Route}

To initiate and maintain a taxi plan, pilots receive a taxi clearance from ATC, cognitively process the clearance, communicate acceptance of the clearance to ATC, and communicate and reinforce the taxi plan within the cockpit. Typically, pilots listen for ATC to address them via their call sign over a shared radio frequency and state their taxi clearance as a list of taxiways and hold instructions. Generally, the pilot-not-taxiing writes down the clearance (or commits it to memory), acknowledges the clearance to ATC by a full read-back, and communicates the clearance to the pilot taxiing. After the taxi route is communicated, pilots formulate a taxi plan of their intended route by integrating the ATC-issued taxi clearance into their knowledge of the airport layout using either a mental map developed by previous experience, or a standard paper north-up airport chart. This includes a plan for the taxiways, holds, and runway crossings required to navigate to their destination.

\section{Making Navigation Decisions}


After the taxi plan has been formulated pilots make a series of navigation decisions (i.e., when and where to turn) based on their understanding of where they are on the airport surface and the distance to, and direction of, their next turn in the clearance. Local awareness information (i.e., signs and markings that indicate where they are on the airport surface) is gathered to enable the task of local guidance or maneuvering the aircraft along the cleared route (Lasswell \& Wickens, 1995; McCann, Foyle, Hooey, \& Andre, 1999). Global awareness is also generated and maintained, which includes awareness of the environment and the airport layout including runways, hold locations, traffic, and concourses (Lasswell \& Wickens, 1995; McCann et al., 1999). Global awareness is important for navigation, as taxi clearances do not typically contain directional information. Therefore, to follow a taxi clearance of "Alpha, Bravo, Charlie," a pilot would have to know which way to turn onto Bravo to reach Charlie.

\section{Executing Navigation Decisions}

Pilots execute their intended taxi plan and navigation decisions by relying on external navigation markings such as airport signage and painted markings on the airport surface including centerlines and hold bars. Airport surfaces consist of a tangled network of taxiways and runways identified by signs and painted markings. As signs cannot be placed overhead (as with our road networks) they are placed on grass and cement islands to the side. Andre (1995) reported that the signs are placed a good distance before the intersection (a good feature that provides preview to the pilots) but not repeated at the intersection (a necessary feature that provides confir mation to the pilots). In fact, at a given intersection, often the only signs visible are those for the next intersection.

\section{TAXI NAVIGATION ERROR TAXONOMY}

Based on the three high-level taxi tasks already described, a taxonomy of pilot error was created (this taxonomy was first presented in Hooey \& Foyle, 2001) that classifies taxi navigation errors into one of three classes: planning errors, decision errors, and execution errors (see Figure 1). Although the taxonomy is sequential in nature, in that the taxi route must first be planned, then navigation decisions are formulated, and then these decisions are executed, it is certainly possible for a pilot to make more than one error in a given taxi operation. Figure 1 also presents examples of observable behaviors surrounding each kind of error. These observable behaviors do not exhaustively categorize all possible factors that may contribute to errors, but they are the most common factors that were determined from the 


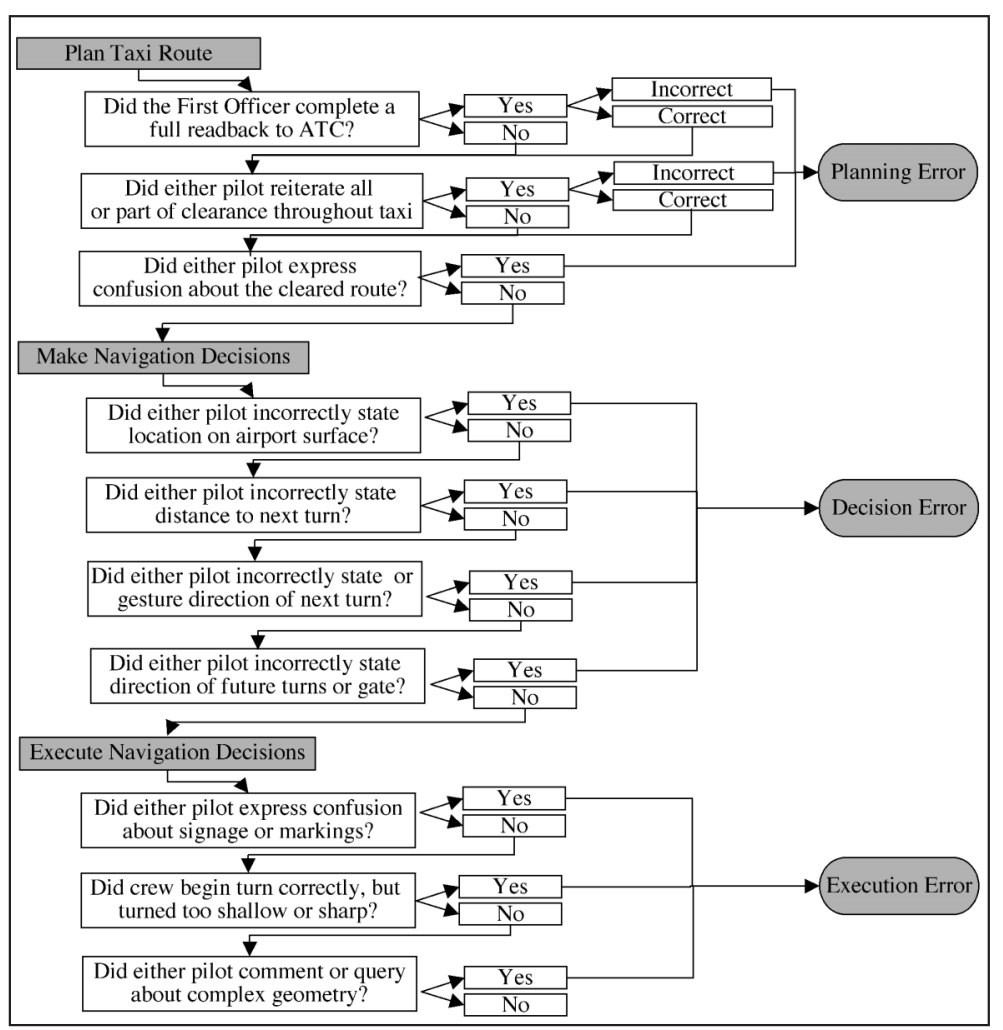

FIGURE 1 Error taxonomy and common, observable behaviors used to classify er-

description of the taxi task and observation of crews in the actual environment and in simulation. These overt behaviors or communications were used to classify each error.

Planning errors occur when the crew formulates an erroneous plan or intention, but carries out the plan correctly. These errors are similar to Reason's (1990) classification of knowledge-based mistakes, which are defined as failing to formulate the right intentions. In any given taxi oper ation, there are multiple opportunities for planning errors to occur. Characteristic behaviors associated with these errors are incomplete or inaccurate reception of the taxi clear ance from ATC (i.e., radio transmission is not clear, or stepped on by another transmission), incorrect read-back of the taxi clearance, and incorrect communication of the clearance within the cockpit. The possibility of a planning error is increased if a pilot does not complete a full read-back of the clearance to ATC, does not write down the clearance, or only communicates part of the taxi clearance to his or her crew. 
Decision error soccur when the clear ance has been properly received, communicated, and planned, but the pilot makes an erroneous choice at a decision point along the route. These are similar to Reason's (1990) rule-based mistakes, particularly those errors that occur when an incorrect action or consequence is chosen. These errors are manifested as turns in the wrong direction, turning where no turn is required, failing to turn when required, or turning at a taxiway before or after the required taxiway. These errors may occur because the crew is unclear of their current location on the airport surface relative to their cleared route, because they are distracted, or if pilots lack an accurate mental map of the airport layout.

Execution errors are those in which the clearance is correctly communicated, pilots identify the correct intersection and direction of the turn, but they err in carrying out the maneuver. These are akin to Reason's (1990) classification of "slips" in which the right intention is carried out incorrectly. Examples of this include following the wrong taxi line at a multiway intersection or taking a hard right turn instead of a soft right turn. These errors may be attributed to confusing environmental cues such as signage or center line markings.

\section{SURFACE OPERATIONS SIMULATION STUDIES}

The preceding error taxonomy was used to analyze taxi navigation errors that occurred during two full-mission surface-operations simulations (Hooey, Foyle, Andre, \& Parke, 2000; McCann et al., 1998) that were conducted to explore the effect of advanced navigation and communication technologies on taxi efficiency and technology usage. Given the low error rate, neither study alone was able to provide insights into error classification, causal factors, and mitigating solutions. However, as both studies were conducted in the same simulation facility and shared common baseline scenarios (current-day operations), the error data from the two studies could be aggregated, providing a rich and unique data set for exploring navigation errors.

Furthermore, the studies allowed for the investigation of the error-mitigating effect of three prototyped technologies: datalink, electronic moving maps (EMMs), and head-up displays (HUDs). Currently, these technologies are the most likely candidates for cockpit integration. Datalink is already integrated into some aircraft and in use in oceanic environments (Kerns, 1990), EMMs can be implemented using existing cockpit displays and are included in the FAA Safe Flight 21 technology roadmap (FAA Safe Flight 21, 2002), and HUDs are installed in many major U.S. carriers and are used regularly for approach and landing (but are typically stowed for surface op- 
TABLE 1

Summary of Simulation Studies

\begin{tabular}{llclc}
\hline Study & Visibility & $\begin{array}{l}\text { No. of } \\
\text { Crews }\end{array}$ & \multicolumn{1}{c}{ Taxi Conditions } & $\begin{array}{c}\text { No. of } \\
\text { Trials/Crew }\end{array}$ \\
\hline $\begin{array}{l}\text { Study } \\
1\end{array}$ & Night & 8 & $\begin{array}{l}\text { Current day/paper chart } \\
\text { only }\end{array}$ & 6 \\
& VMC & & EMM & 6 \\
RVR 700' & 8 & EMM + HUD & 6 \\
2 & RVR 1000' & 18 & Current day/paper chart & 3 \\
& & & only & Datalink \\
& & & Datalink + EMM + HUD & 3
\end{tabular}

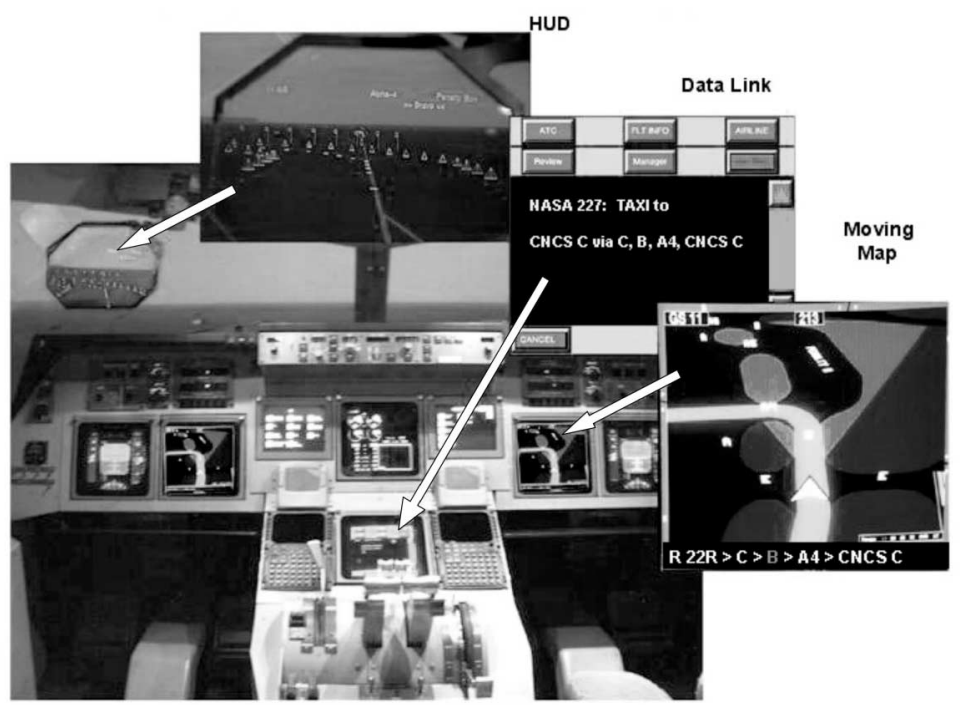

FIGURE 2 NASA prototype surface operations technologies integrated into the Advanced Concept Flight Simulator (ACFS) cockpit. The figure shows insets of the head-up display (top left), datalink interface on lower EICAS (middle), and electronic moving map

erations). NASA's full-mission simulation facility, the Advanced Concept Flight Simulator (ACFS), and details of both simulation studies are described briefly next. Table 1 provides a summary of the taxi conditions examined in the two simulation studies.

\section{Surface Operations Full-Mission Simulation Facility}


Both simulations were conducted in NASA's ACFS (shown in Figure 2) which is a generic glass cockpit simulator with a full six degree-of-freedom motion system. The image generator provides a $180^{\circ}$ field of view and a high-fidelity representation of Chicago O'Hare Airport replicating the airport layout, signage, painted markings, lights, concourses, and structures. The experimental ATC facility allows for a highly realistic representation of current-day surface operations by integrating confederate (experimenter) local and ground controllers. Pseudo-pilots provide ATC and background party-line communications that are synchronized to the movement of the computer-controlled airport traffic.

The ACFS was equipped with datalink for routine surface oper ations communications, head-down EMMs that depicted the air port surface and the taxi clearance both textually and graphically, and an HUD that depicted taxi clearance information. Each of these technologies, shown in Figure 2, is described next.

Datalink. Datalink allows for the electronic transmission of routine clearance information between air traffic controllers and pilots (see Kerns, 1990). Although not currently used for surface operations, it has been proposed that the use of datalink may be extended to include routine sur face operations clearances such as taxi clearances, hold commands, and route amendments (Hooey et al., 2000). In the NASA prototype, similar to en-route datalink systems currently in use today, pilots were notified of a new datalink text message by both an auditory chime and a visual text message in the upper Engine Instrument Crew Alerting System (EICAS) display. The full-text readout appeared on the lower EICAS display (see datalink interface in Figure 2). Either pilot could view the datalink message and access a log of previous messages. The phraseology of the taxi clearance issued via datalink was identical to that currently issued by voice. It is expected that presenting an unambiguous record of the taxi clearance into the cockpit would aid the taxi-planning stage and minimize the potential for errors associated with hearing, writing, remembering, and communicating the taxi clearance.

Head-down EMM. Another technology that has been proposed for surface operations navigation is the use of head-down or panel-mounted EMMs. An example is the EMM developed for the Taxiway Navigation and Situation Awareness (T-NASA) system (Foyle et al., 1996; Hooey, Foyle \& Andre, in press). This EMM depicts the taxi clearance both graphically and textually. Graphically, the EMM depicts the air port layout including labeled taxiways, runways, and concourses. The cleared taxi route is presented graphically as a magenta path. The ownship icon is updated in real time and depicts the location of the ownship relative to the air port features and the cleared route. Tex- 
tually, the text clearance window presents the actual taxi clearance, and the taxi segment on which the aircraft is currently taxiing is highlighted in magenta. The text box also displays the distance to the next turn or hold location. It is expected that the text clearance will help pilots in the taxi-planning phase and, like datalink, will minimize problems associated with receiving and communicating the taxi clearance. Furthermore, it is expected that the EMM would improve navigation by clearly depicting the current position of the aircraft relative to the cleared taxi route, as well as the direction of, and distance to, the next navigation decision point.

HUD. The HUD presents symbology on a combiner glass so that the infor mation appears to be projected over the view of the world beyond the cockpit. In current-day commercial aircraft, HUDs are typically mounted in front of the left seat, for use by the captain only. HUDs are typically used only during takeoff and landings, however, it has been proposed that HUDs could be an effective display for navigation infor mation on the air port surface as well (Foyle et al., 1996). One such example is the HUD symbology that has been incorporated into the T-NASA system (see Hooey et al., in press). This HUD, as shown in Figure 1, uses scene-linked symbology to depict the center line and the sides of the ATC-cleared taxiways (Foyle et al., 1996). Local route guidance (information required for immediate navigation tasks) is implicitly embedded in the symbology as the scene-linked symbols only outline the cleared route (see McCann et al., 1999). The symbology provides predictive information about the cleared route (i.e., distance and direction of next turn) that is not always available in the environment, even in good visibility conditions. It is expected that providing this infor mation will assist the pilot in making navigation decisions as well as executing the determined taxi plan.

\section{Surface Operations Simulation Study 1}

In the first study (McCann et al., 1998), 16 two-pilot commercial crews completed 18 land and taxi-to-the-gate scenarios at the simulated Chicago O'Hare Airport. All pilots were current on glass-equipped aircraft with a mean of 3,612 hr logged. Seven captains and seven first officers (FOs) reported that they regularly flew into Chicago O'Hare on at least a monthly basis. The taxi routes from the runway to the gate required approximately 3 min to taxi. Each crew completed six trials in current-day operations with only a paper airport chart for navigation, six trials with an EMM, and six trials with both an EMM and HUD. Each set of three successive trials contained one of each navigation aid condition, and the order was randomly assigned for each crew. Half of the crews (8) completed the trials in 
low-visibility conditions (runway visual range [RVR] $700 \mathrm{ft}$ ) and half completed the trials in night visual meteor ological conditions (VMC).

\section{Surface Operations Simulation Study 2}

In the second simulation (Hooey et al., 2000), 18 two-pilot commercial crews completed nine nominal land and taxi-to-the-gate scenarios at O'Hare Airport in RVR 1,000 ft conditions. All pilots were current in glass-equipped aircraft with a mean of 2,645 hr logged. Five captains and six FOs reported that they regularly flew into O'Hare on at least a monthly basis. The scenarios were similar to Study 1 and required approximately 3 min to taxi from runway to gate. Each crew completed three nominal trials in current-day operations with voice communications and a paper chart for navigation, three with datalink text clearances and the paper chart, and three with datalink text clearances and both the EMM and HUD for navigation. The order of these three experimental blocks was assigned using a Latin square, and the order of trials within each block was randomized with constraints. Additional off-nominal event trials that included near incursions, clearance errors, and system failures were completed but are not included in these analyses, as these events may have affected navigation performance on those trials.

\section{ERROR ANALYSIS METHODOLOGY}

Each trial from both simulation studies was analyzed for the occurrence of a navigation error defined as taxiing on a portion of the airport surface on which the aircraft had not been cleared, and deviating from the cleared taxiway centerline by at least $50 \mathrm{ft}$. This was determined using simulation data output that provided a measure of aircraft distance from taxiway centerline. A team of three reviewers analyzed each trial using a combination of the following: (a) real-time observation from the simulator jumpseat or experimenter control station; (b) simulation replays depicting the position of the aircraft on the airport; (c) quad-split videotape depicting the out-the-window simulation scene, the captain, the FO, and the relevant cockpit displays; and (d) cockpit audio recordings of pilot-ATC communication and intracockpit communication synchronized to the video. Unanimous agreement among reviewers was reached regarding the occurrence of a navigation error, the taxi clearance as issued by ATC, and the location of the error on the airport surface. Subsequently, the videotapes were analyzed to classify each error as a planning error, decision error, or execution error based on the criteria and observable behaviors presented in Figure 1. In the actual taxi environment, pilots are encouraged to communicate their 
FIGURE 3 Percentage of errors in each error class: Planning, decision, and execution.

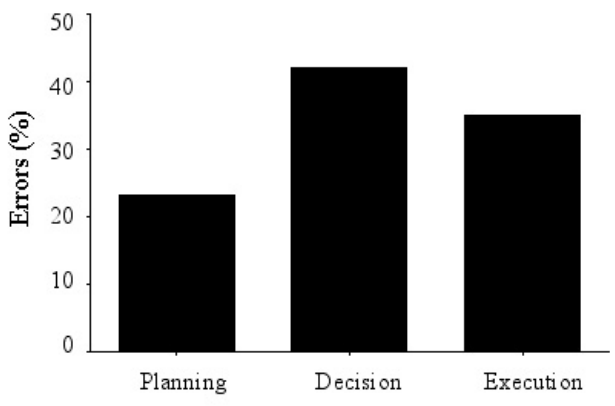

understanding of the clearance, their location on the airport surface, and the required navigation maneuvers. These practices and procedures resulted in overt behaviors and communications in the simulations that were used to classify the errors. Where necessary, posttrial or poststudy debriefs were used to further understand the nature of the error. In addition, an analysis was conducted to identify all potentially relevant actions, comments, and behaviors that could have contributed to the error.

\section{RESULTS}

Of the 150 current-operation trials across the two simulation studies, 26 $(17.3 \%)$ contained a single navigation error (none contained more than one error). Using the error taxonomy shown in Figure 1, each of the 26 errors was classified as one of the following: planning, decision, or execution errors. These were observed in roughly equal proportions, as shown in Figure 3. A multinomial Bayesian analysis (see Appendix) revealed no statistical differences among the error categories, however decision errors were committed more frequently than planning errors with a marginal posterior probability of .88 .

In the following sections, the errors that occurred in current-day operations trials are examined and contributing factors that were prevalent for each error class are suggested. Also, simulation trials in which pilots taxied with datalink, EMM, EMM + HUD, or datalink + HUD + EMM are examined to determine the degree to which each technology mitigated error. For each class of error, a Bayesian logistic regression ${ }^{1}$ was fit to the error data with vis-

\footnotetext{
${ }^{1}$ Noninformative nor mal prior distributions with mean zero and variance 1,000 were used on all $\log$ odds ratios and the intercept log odds. The data from all experimental conditions were augmented by one committed error to reduce the extreme sparseness of the contingency table. Posterior summaries were calculated using Markov chain Monte Carlo methods in the software Bayesian Inferences Using Gibbs Sampling (Thomas, 1994). Convergence of the Markov chain was noted after 1,000 samples, and 10,000 further samples were generated for the posterior
} 
TABLE 2

Planning Errors: Descriptions and Causal Factors

\begin{tabular}{|c|c|c|}
\hline Error & Description & Causal Factors \\
\hline 1 & $\begin{array}{l}\text { Readback error, FO read back clearance } \\
\text { incorrectly, captain followed FO's } \\
\text { incorrect clearance }\end{array}$ & Read-back error; miscommunication \\
\hline 2 & $\begin{array}{l}\text { FO communicated erroneous clearance } \\
\text { to captain }\end{array}$ & $\begin{array}{l}\text { Miscommunication; Confusion with } \\
\text { another clearance }\end{array}$ \\
\hline 3 & $\begin{array}{l}\text { Crew correctly received clearance, but } \\
\text { later erroneously modified route by } \\
\text { substituting an incorrect taxiway in the } \\
\text { clearance }\end{array}$ & $\begin{array}{l}\text { Expectation bias (erroneously } \\
\text { substituted a taxiway that was a more } \\
\text { direct route to gate) }\end{array}$ \\
\hline 4 & $\begin{array}{l}\text { Crew correctly received clearance, but } \\
\text { later erroneously modified route by } \\
\text { omitting one segment of the clear ance }\end{array}$ & $\begin{array}{l}\text { Expectation bias (erroneously } \\
\text { substituted a taxiway that was a more } \\
\text { direct route to gate) }\end{array}$ \\
\hline 5 & $\begin{array}{l}\text { Crew correctly received clearance, but } \\
\text { later erroneously modified route by } \\
\text { omitting one segment of the clearance }\end{array}$ & $\begin{array}{l}\text { Expectation bias (erroneously } \\
\text { substituted a taxiway that was a more } \\
\text { direct route to gate) }\end{array}$ \\
\hline 6 & $\begin{array}{l}\text { Crew correctly received clearance, but } \\
\text { later erroneously modified route by } \\
\text { omitting one segment of the clearance }\end{array}$ & $\begin{array}{l}\text { Expectation bias (erroneously } \\
\text { substituted a taxiway that was a more } \\
\text { direct route to gate) }\end{array}$ \\
\hline
\end{tabular}

ibility and technology as predictors. For each analysis, a posterior probability is provided that indicates the probability that the error rate observed with the technology was lower than the error rate observed in the current-day operations trials. Posterior probabilities that are .95 or greater are considered strong evidence that the technology did reduce error rates compared to baseline conditions. Posterior probabilities between .90 and .95 are considered moder ate evidence that the technology reduced error rates compared to baseline conditions.

\section{Planning Errors}

Planning errors are errors in which the pilot formulated an erroneous plan or intention, but carried out the plan correctly. Planning errors accounted for 23\% (6 of 26) of all errors made in the 150 current-day baseline conditions across both studies. In these instances, pilots formulated and verbalized an erroneous taxi plan, or inadvertently modified a taxi plan, and then made navigation decisions based on the incorrect plan. Table 2 provides a description of each error and the causal factors that were attributed to the error.

Although many factors likely inter act to contribute to planning errors, two prevalent contributing factors were identified: miscommunication and the de- 
velopment of er roneous routing expectations. Miscommunications between pilots and ATC or between crew members during the initial communication of the clearance contributed to two of the planning errors. In four of the errors, the taxi plan was inadvertently altered during a crew communication midway through the route, even though ATC issued the clear ance cor rectly and the FO initially read it back correctly. It is likely that these pilots had formulated expectations based on their previous exper ience and knowledge of the air port layout and destination concourse and doubted their understanding of the clearance when it conflicted with their expectations. Their solution was to omit or change the conflicting taxiway in the clearance.

Mitigating planning errors. Planning error soccurred because pilots formulated an incorrect understanding of the taxi clearance. Therefore, it is reasonable to hypothesize that presenting the clear ance in a clear and unambiguous manner that is readily available in the cockpit while taxiing might mitigate these errors. The full-mission simulations included trials in which pilots taxied with datalink, EMM, EMM + HUD, and EMM + HUD + datalink. All of these technology combinations provided a clear and continuous representation of the clear ance either textually (datalink) or graphically (EMM). By examining planning error rates with these technology combinations it is possible to estimate the effectiveness of providing these kinds of information to the pilots.

As can be seen in Figure 4, there were no planning errors observed with any of the technologies present in the cockpit. There is evidence that the EMM reduced planning errors compared to baseline (.94 posterior probability) as did the EMM + HUD (.94 posterior probability). The EMM depicted the cleared route both graphically (via a magenta path overlaid on the perspective view of the airport surface) and textually (as a text display on the bottom of the map). This graphical and textual representation presumably helped mitigate misunderstandings and confusions regarding the cleared route.

FIGURE 4 Planning errors: Formulating an erroneous taxi plan.

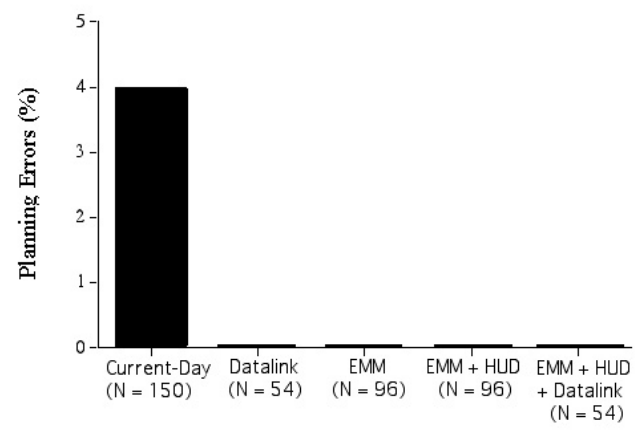


TABLE 3

Decision Errors: Descriptions and Causal Factors

\begin{tabular}{|c|c|c|}
\hline Error & Description & Causal Factors \\
\hline 1 & Turned left instead of right & Lacked global awareness of airport layout \\
\hline 2 & $\begin{array}{l}\text { Turned left, no turn } \\
\text { required }\end{array}$ & $\begin{array}{l}\text { Workload (first turn after runway exit); lacked } \\
\text { awareness of position on airport surface }\end{array}$ \\
\hline 3 & Turned left instead of right & $\begin{array}{l}\text { Lacked global awareness of airport layout; } \\
\text { miscommunication-Captain and FO did not share a } \\
\text { common understanding of airport layout }\end{array}$ \\
\hline 4 & $\begin{array}{l}\text { Turned right, no turn } \\
\text { required }\end{array}$ & $\begin{array}{l}\text { Workload (first turn after runway exit); lacked } \\
\text { awareness of position on airport surface }\end{array}$ \\
\hline 5 & Turned left instead of right & $\begin{array}{l}\text { Workload (first turn after runway exit); lacked } \\
\text { awareness of position on air port surface; lacked } \\
\text { global awareness of airport layout }\end{array}$ \\
\hline 6 & Turned left instead of right & $\begin{array}{l}\text { Workload (first turn after runway exit); FO occupied } \\
\text { with ATC; lacked global awareness of airport layout }\end{array}$ \\
\hline 7 & Turned left instead of right & $\begin{array}{l}\text { Lacked global awareness of airport layout and } \\
\text { concourse location }\end{array}$ \\
\hline 8 & Turned left instead of right & $\begin{array}{l}\text { Workload (first turn after runway exit); lacked } \\
\text { global awareness of airport layout }\end{array}$ \\
\hline 9 & $\begin{array}{l}\text { Failed to turn into } \\
\text { concourse }\end{array}$ & $\begin{array}{l}\text { Lacked global awareness of concourse location; FO } \\
\text { occupied, head down with paper chart }\end{array}$ \\
\hline 10 & Turned left instead of right & Lacked global awareness of airport layout \\
\hline 11 & $\begin{array}{l}\text { Chose to taxi straight, } \\
\text { rather than turning left } \\
\text { (pilots had come to a stop, } \\
\text { and actively decided to taxi } \\
\text { straight) }\end{array}$ & $\begin{array}{l}\text { Workload (first turn after runway exit); lacked } \\
\text { awareness of location on air port surface; FO } \\
\text { occupied with ATC and head down looking at paper } \\
\text { chart }\end{array}$ \\
\hline
\end{tabular}

As seen in Figure 4, no planning errors occurred in the datalink condition (.88 posterior probability) and datalink + EMM + HUD condition (.88 posterior probability). That the posterior probability suggests only weak evidence (at best), may be indicative of the lower number of trials tested in these conditions, as compared to the EMM, and EMM + HUD conditions. Given that no errors were observed, it is likely that datalink mitigates planning errors to some extent by reducing communication problems and allowing pilots to make frequent checks of the datalink clear ance while taxiing, and this minimized the possibility of midroute substitution and omission errors. These data suggest that the presentation of the clearance in any form mitigated planning errors.

Decision Errors 
Decision errors occurred when the route had been properly received, communicated, and planned (as evidenced by a correct full read-back to ATC and intracockpit communication), but the pilot made an erroneous choice at a decision point along the route. Most often this was observed as a turn in the wrong direction, such as turning left when they should have turned right or vice versa. Pilots formulated and verbalized the correct taxi plan, but failed to make the correct navigation decision to accomplish their goal. There were 11 occurrences of this type of error across the 150 current-day operation trials accounting for $42 \%$ of all errors observed. Table 3 provides a description of each error and the causal factors that were attributed to the error.

Excessive operational demands and inadequate navigational awareness were identified as two of the major contributing factors to these errors. Of the 11 decision errors in current-operation trials, 7 occurred at the first decision point encountered after exiting the runway. Often, the FO was occupied with his or her tasks (changing radio frequencies, contacting ground control, receiving the taxi clearance, writing it down, reading it back to ATC, checking the paper chart, and communicating the route to the captain), and the captain was pressured to clear the runway and sometimes began taxiing before the FO was ready to assist with navigation (see also Parke, Kanki, McCann, \& Hooey, 1999). In 4 of the 11 decision errors, uncertainty of the aircraft position on the air port surface was identified as a contributing factor. Pilots made navigation decisions assuming they were somewhere on the airport surface that they were not. In 7 of the 11 errors, pilots were aware of their location on the airport surface but made a turn in the wrong direction, demonstrating a poor understanding of their location relative to their destination concourse, or poor global awareness of the airport layout.

Mitigating decision errors. The percentage of decision errors associated with each advanced navigation display condition is presented in Figure 5. Given

FIGURE 5 Decision errors: Choosing an incorrect action.

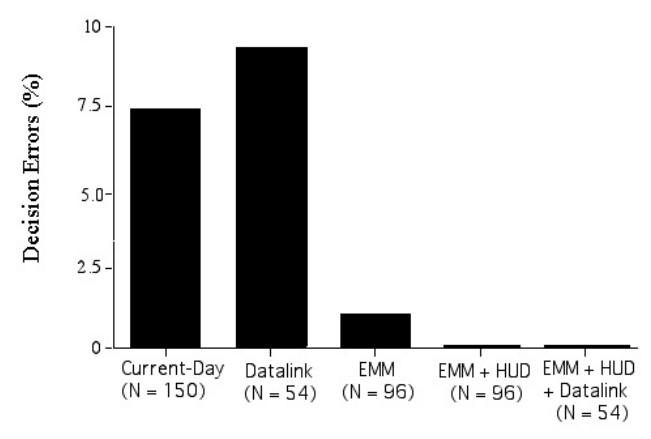


the nature of decision errors, it was expected that decision errors would be mitigated by technologies that decrease workload at runway turnoff and that contribute to a pilot's navigational awareness by providing both local and global awareness including infor mation about the distance to and direction of the next required turn. The EMM and HUD, when presented together, were designed to provide this infor mation. This data set provided an opportunity to examine error rates with these technologies, as compared to trials on which pilots received no additional local or global awareness infor mation (i.e., the current-day operation trials, and datalink trials).

As can be seen in Figure 5, decision errors were eliminated when pilots were provided with both local and global awareness infor mation (i.e., with the EMM + HUD, .97 posterior probability; and datalink + EMM + HUD, .99 posterior probability). Together the EMM and HUD provided a clear indication of the location of ownship relative to the cleared route (local guidance provided by the HUD) and the direction of the cleared turn or destination concourse (global awareness provided by the EMM).

The EMM alone reduced decision errors compared to the baseline condition (.92 posterior probability), but not as much as when it was paired with

TABLE 4

Execution Errors: Descriptions and Causal Factors

\begin{tabular}{|c|c|c|}
\hline Error & Description & Causal Factors \\
\hline 1 & Misread signage & $\begin{array}{l}\text { Confusing placement of taxiway sign; } \\
\text { taxiway changed names but not } \\
\text { directions }\end{array}$ \\
\hline 2 & Misread signage and taxiway markings & $\begin{array}{l}\text { Confusing placement of taxiway sign; } \\
\text { confusing markings at multiway } \\
\text { intersection }\end{array}$ \\
\hline 3 & $\begin{array}{l}\text { Began executing correct turn, but } \\
\text { followed wrong centerline and turned } \\
\text { too far }\end{array}$ & Confusing centerline markings \\
\hline 4 & Misread signage and taxiway markings & $\begin{array}{l}\text { Confusing placement of taxiway signs; } \\
\text { confusing markings at multiway } \\
\text { inter section }\end{array}$ \\
\hline 5 & Failed to follow center line & $\begin{array}{l}\text { Difficulty seeing markings (in night } \\
\text { condition) }\end{array}$ \\
\hline 6 & $\begin{array}{l}\text { Followed wrong center line while } \\
\text { executing turn }\end{array}$ & $\begin{array}{l}\text { Confusing centerline markings at } \\
\text { concourse area }\end{array}$ \\
\hline 7 & $\begin{array}{l}\text { Followed wrong centerline while } \\
\text { executing turn }\end{array}$ & $\begin{array}{l}\text { Confusing markings; taxiway changes } \\
\text { names, but not direction }\end{array}$ \\
\hline 8 & $\begin{array}{l}\text { Followed wrong center line while } \\
\text { executing turn }\end{array}$ & $\begin{array}{l}\text { Confusing markings at location with } \\
\text { many closely spaced taxiway } \\
\text { intersections }\end{array}$ \\
\hline
\end{tabular}


the HUD. The EMM by itself provided effective global awareness but was less effective for local guidance. In the one decision error that was observed in the EMM condition, the pilot was cognizant of the route, on which taxiway the turn was required, and the direction of the turn, but passed the required intersection expecting to tur $n$ at the following inter section demonstrating a lack of awareness of his current position relative to his required taxiway. The pilot remarked that he did not realize the turn was as close as it was. Presumably, this error occurred because the EMM required pilots to make a translation from their position on the map to their position on the air port surface. Also, in this case, the captain was taxiing without support from the FO who, at the time of the error, was busy communicating with ATC.

Also noteworthy in Figure 5 is that five decision errors occurred in the 54 trials in which pilots had datalink but not the EMM or HUD displays, representing an error rate of $9.3 \%$. There was little evidence that datalink mitigated decision errors (.62 posterior probability). Datalink served to clarify the issued taxi clear ance but because it did not provide local or global awareness, it did little to guide pilots at each decision point.

\section{Execution Errors}

Errors of execution are those in which pilots developed correct taxi plans and navigation turn decisions (as evidenced by a correct read-back of the clearance to ATC and intracockpit communication that identified the correct intersection and direction of the turn) but erred in carrying out the maneuvers. There were nine execution errors that accounted for $35 \%$ of all errors in the current-day operation trials across the two studies. Table 4 provides a description of each error and the causal factors that were attributed to the error.

Several factors contributed to these errors including complex taxiway geometry, confusing signage, and the "sea of blue lights" phenomenon (see also Adam \& Kelley, 1996; Andre, 1995). In all cases, the envir onmental cues were inadequate or misleading. Navigating complex taxiway geometry such as intersections with multiple inter secting taxiways, taxiways that changed names but not direction, and inter sections that possessed two or more turns in the same direction but at different angles accounted for $78 \%$ (seven of nine) of the execution errors. The most frequent factor associated with these errors of execution was a failure to disambiguate the multiple center lines painted on the airport surface. Not only was it difficult for pilots to discern which was the cor rect center line to follow, it was also difficult for the FO to decipher the paper airport chart, relate the infor mation on the paper chart to the world, and communicate the information to the captain. 


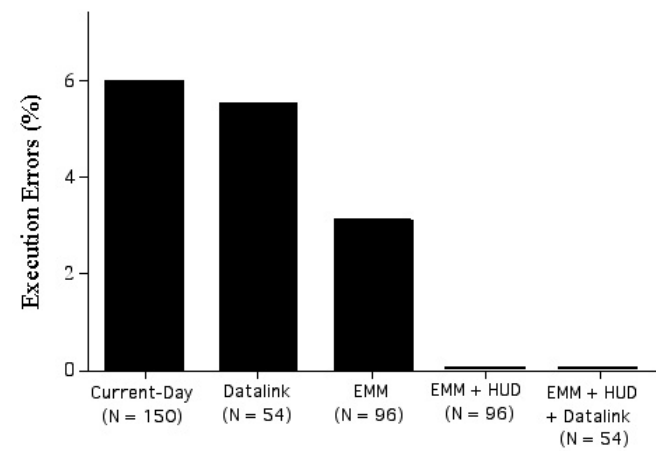

FIGURE 6 Execution errors: Incorrectly executing a turn.

TABLE 5

Summary of Error Classes, Contributing Factors, and Mitigating Solutions

\begin{tabular}{|c|c|c|c|}
\hline Error & Planning (23\% of Errors) & Decision (37\% of Errors) & Execution (31\% of Errors) \\
\hline Examples & $\begin{array}{l}\text { No or partial clearance } \\
\text { No or partial readback } \\
\text { Did not write clearance, } \\
\text { or incorrect } \\
\text { For got or inadvertently } \\
\text { changed clearance } \\
\text { Received clearance late }\end{array}$ & $\begin{array}{l}\text { Failed to turn } \\
\text { Turned wrong direction } \\
\text { Turned where not } \\
\text { required } \\
\text { Turned too early or too } \\
\text { late }\end{array}$ & $\begin{array}{l}\text { Followed wrong sign } \\
\text { Followed wrong taxiway } \\
\text { centerline }\end{array}$ \\
\hline $\begin{array}{l}\text { Main } \\
\text { causes }\end{array}$ & $\begin{array}{l}\text { Miscommunication } \\
\text { Erroneous expectations }\end{array}$ & $\begin{array}{l}\text { Excessive workload } \\
\text { Poor global awareness } \\
\text { Poor local guidance }\end{array}$ & $\begin{array}{l}\text { Complex geometry } \\
\text { Confusing signage } \\
\text { Poor visibility }\end{array}$ \\
\hline $\begin{array}{l}\text { Mitigating } \\
\text { solutions }\end{array}$ & $\begin{array}{c}\text { Provide unambiguous } \\
\text { clearance readily } \\
\text { available in cockpit }\end{array}$ & $\begin{array}{l}\text { Reduce workload } \\
\text { Enhance global } \\
\quad \text { awareness } \\
\text { Enhance local guidance }\end{array}$ & $\begin{array}{l}\text { Disambigate } \\
\text { environment } \\
\text { Enhance local guidance }\end{array}$ \\
\hline $\begin{array}{l}\text { Technolog } \\
\text { yexampl } \\
\text { es }\end{array}$ & Datalink, EMM & EMM + HUD & HUD \\
\hline
\end{tabular}

Pilots reported confusion regarding the taxiway signage, even though the signage in the simulator replicated the actual O'Hare signage in content, size, and location on the airport surface. At most airports, including Chicago O'Hare, signs can only be placed on grass or concrete islands beside the taxiways. As such, it is sometime difficult to discern which taxiway corresponds with the angle on a sign. This confusion contributed to navigation errors in the two simulations. 
Mitigating execution errors. As discussed earlier, confusing cues play the largest contributing role in execution errors. Ther efore, it is reasonable to expect that these er ror s would be mitigated by augmenting the cleared route in the environment. The taxi HUD is one means of accomplishing this as it presents the center line and sides of the cleared taxi route and natur ally disambiguates the correct and incorrect center lines.

As can been seen in Figure 6, execution er ror s were eliminated when taxiing with the HUD, specifically the EMM + HUD trials (.97 posterior probability) and the EMM + HUD + datalink trials (.97 posterior probability). In contrast, the EMM alone and datalink alone conditions had little mitigating effect on the probability of execution er ror s compared to baseline conditions. Of the 96 trials that were completed with the EMM alone, $3(3.1 \%)$ contained errors of execution, showing only a slight reduction over current oper ation error rates $(.73$ poster ior probability). It is likely that the EMM assists pilots in navigating complex inter sections and inter preting signage, but it does not always disambiguate the envir onment immediately before the pilot. Also, in the three er ror trials, the captains were taxiing without support from the FO, who was communicating with ATC, and exhibited difficulty utilizing the head-down EMM while taxiing. There were three execution errors with datalink alone (5.5\% of the 54 datalink trials), again showing only a slight reduction over current operation error rates (.65 posterior probability). It is not surprising that datalink contributed little to mitigating execution errors, as it served to communicate the taxi clearance but did not disambiguate the external environment for the pilots.

\section{Summary of Results}

A taxonomy of taxi navigation errors was developed and applied to navigation errors observed during two full-mission simulation studies of surface operations. Each of three classes of error (planning, decision, and execution) was associated with a unique set of contributing factors and mitigated by a unique set of technologies. Datalink effectively eliminated planning errors, but did not reduce decision or execution errors. The EMM, in addition to reducing planning errors, also contributed to a reduction in decision errors. The HUD and EMM + HUD combination were most effective, eliminating planning, decision, and execution errors altogether. Table 5 summarizes the contributing factors and the technologies that were most effective at mitigating each class of error.

DISCUSSION 
The analysis revealed several factors that contribute to planning, decision, and execution errors. From this analysis, potential solutions were identified that might successfully mitigate these errors in current-day operations. In addition, the analysis offers empirical data to aid the decision-making process as to which technologies should be integrated into the cockpit, and how to prioritize this integration process. By considering the causal factors, and generalizing from the characteristics inherent in the technologies that were effective, a range of solutions to mitigate planning, decision, and execution errors is proposed.

\section{Causal Factors and Implications for Current-Day Operations}

Given the analysis of causal factors, potential procedures and changes to operations that target these causal factors are proposed.

Miscommunication. Planning errors occurred because pilots did not have a clear or correct understanding of their taxi route or inadvertently modified their taxi clear ance. This observation lends support for the following procedures recommended in the FAA Advisory Circular (FAA, 2001): (a) Pilots should always write down the entire clear ance and use these instructions during a pretaxi briefing and to reconfir $m$ the taxi route during taxi, and (b) pilots should always complete a full read-back of the clearance to ATC and ask for clarification when in doubt. This serves to ensure that pilots have a correct record of the clear ance, and the verbal repetition of the clear ances provides an opportunity to reinforce the correct route for both pilots. It would seem that these procedures offer a low-tech solution to realize a reduction in planning errors.

Erroneous expectations. It was observed that pilots tended to doubt their understanding of the clearance when it seemed to deviate from their expectations and instead follow a rule set developed from experience. Because pilots' expectations are based in part on knowledge of the airport layout and past experiences at the air port, this suggests that a route that deviates from pilots' expectations may leave very experienced pilots prone to planning errors, even more so than pilots who are unfamiliar with the air port layout. It is hoped that awareness of this tendency will encour age pilots to question their assumptions and ask for clarification when in doubt. Also, armed with this knowledge, the pilot not taxiing and ATC may be encour aged to highlight unexpected deviations in nor mal oper ations to ensure that the taxiing pilot is cognizant of the deviation.

Inadequate situation awareness. 
Not surprisingly, errors occurred when pilots exhibited a loss of situational awareness and confusion over location of taxiways, gates, and runways. The observed lack of awareness of ownship position on the airport surface (i.e., crews thinking they were somewhere and they were not) support the FAA-recommended procedures (FAA, 2001) emphasizing continual verbalization between $\mathrm{FO}$ and captain regarding their current taxiway, upcoming taxiways, and distance and direction of upcoming decision points.

Excessive workload. Navigation errors occurred most frequently on the first turn (after exiting the runway). Pressure to clear the runway to ensure safety and organizational pressure to taxi to the gate quickly (Hooey et al., 1999) make it difficult for pilots to take the time necessary to develop an awareness and understanding of the cleared route. Also, this first turn coincides with requirements for ATC communication, which distracts the FO from the navigation task. Furthermore, the workload in the simulation was quite minimal compared to actual operations. In reality, pilots must also contact their company for a gate assignment, often handle changes in gate assignments, complete postlanding checklists, reconfigure the aircraft, and communicate with cabin crew, passengers, and company.

One operational change that is worthy of consideration to alleviate the high-workload runway exit choke point is air borne taxi clear ances (see Hooey et al., 2000) or at least providing the first taxiway while air borne (as suggested by Adam \& Kelley, 1996). Assuming such a clear ance could be issued well in advance of the critical final approach phase, it would allow pilots to for mulate and brief a taxi plan and deter mine and rehearse the ear ly tur n decisions before exiting the runway.

Confusing environmental cues. Many errors (mostly execution errors) were attributed to inadequate or confusing signage and centerline markings, and complex air port geometry. The FAA has developed standards for signage and markings that are adhered to at most airports (and in the simulations). However, given the complexity of the taxiway geometry (Andre, 1995), and inconsistencies among airports (Adam \& Kelley, 1996), confusion still arises. Also, it was observed in the Chicago O'Hare simulations that execution errors tend to occur when a pilot has to choose between two or more turn options in the same direction, and when a taxiway changes name, but not direction. This was prominent in the night condition trials when the "sea of blue" effect was observed, in which the blue lights that mark the taxiways caused pilots to become disoriented particularly when viewed off-axis (Adam \& Kelley, 1996; McCann et al., 1998). Although it is possible that these navigation errors may have occurred due to an artifact of the simulation fidelity, this is unlikely. Par- 
ticipants assessed the fidelity of the simulation to be high, and reported that it realistically replicated real-world operations.

Each air port likely has unique char acter istics of geometry and signage that lend itself to execution errors that can be readily identified. Promoting an awar eness of potential "hot spots" or confusing ar eas on the air port surface via training or advisory circulars may be a simple strategy to help mitigate the more common execution er ror s. If the pilot not taxiing is aware of these potential hot spots, he or she can provide better guidance to the pilot taxiing such as "next right, 45 degrees" or "hard left" to avoid the common mistakes. Programs to address this problem may include analysis and communication of common error locations on airport surfaces, multimedia applications that allow pilots to practice navigating various air port environments, and more taxi time in regular pilot simulation training programs.

\section{Implications for Technology Implementation}

One of the goals of this analysis was to provide data to support the logical progression of technology into the cockpit; that is, to deter mine which (if any) cockpit technology would offer benefits to surface operations by reducing navigation errors. Three classes of technology were explored in the two simulations: datalink, with textual representations of the taxi clearance; EMMs, with gr aphical representations of the air craft relative to the air port surface features and cleared route; and HUDs, with conformal over laid representations of the cleared route. The merits of each, and consideration for integration into the cockpit, are reviewed next.

Datalink. Datalink presents the taxi clearance in a clear, unambiguous, and readily available format in the cockpit throughout the entire taxi route. However, the data revealed that datalinked taxi clearances only served to eliminate planning errors (which accounted for only about $23 \%$ of all observed errors), but did not mitigate either decision errors or execution errors, which make up the remaining $77 \%$ of errors.

It should be noted that, as implemented, datalink showed little benefit for reducing decision errors. However, it could be more effective if the datalink text message was modified to include additional navigational awareness information. For example, many decision errors occurred when pilots identified the correct turn location, but turned in the wrong direction. It is possible that simply including the turn direction in the datalink communication could mitigate these errors. Providing turn direction in the clearance is currently not provided in voice clearances given ATC workload and radio congestion, but could be easily accomplished with datalink. Datalink also offered the benefit of reduced miscommunication (see Parke et al., 2001). 
EMMs. The EMM provided pilots with a perspective view that depicted the air port layout, the cleared taxi route, and an icon of their aircraft location updated in real time. Because it also offered a text read-out of the clearance, it was equally as successful as datalink at mitigating planning errors. However, in addition, the EMM provided the benefit of eliminating most decision errors by providing awareness of ownship location and a graphical depiction of the cleared route that minimized confusion regarding the required direction of a turn.

It is important to note that the additional benefit of reduced decision errors was derived from the combination of the depiction of ownship location and the cleared route. For example, if the map only showed the ownship location overlaid on a map of the air port layout, pilots would still be required to under stand the clear ance, for mulate a mental image of their route, and potentially perform mental rotation of the map to deter mine the direction of their turn. Similarly, if the map only showed the cleared route, but was not capable of depicting real-time ownship location, the benefit for decision er ror s would be minimized. This suggests that cockpit maps that do not depict both ownship location and cleared route will not be as successful at reducing navigation errors on the airport surface as the EMM tested in the simulations.

HUDs. The HUD provided a conformal depiction of the cleared route and was the most promising technology of those tested. In fact, no errors occurred at all when pilots were taxiing with the HUD. However, two issues are worth noting about HUD integration. First, the HUD symbology tested in the simulations was conformal scene-linked symbology (see Foyle, McCann \& Shelden, 1995). Recent empirical studies have shown that nonconfor mal guidance symbology may introduce safety concerns of lower situation awareness, higher workload, and cognitive tunneling (Foyle, Hooey, Wilson, \& Johnson, 2002). The second issue is that the HUD depicted only the cleared taxi route and it was this feature that allowed pilots to easily disambiguate the environment (i.e., deter mine which center line to follow). A differ ent HUD implementation, such as one in which all taxiway center lines are augmented in the HUD (as has been suggested as a near-term solution until routes can be uplinked from ATC to the cockpit), likely would not offer the same error reduction. This is an important distinction, and it implies that industry must work to develop technologies to either transmit the cleared taxi route from ATC into the cockpit HUD (e.g., datalink) or allow for pilots to input the route in a safe and efficient manner. Other wise, these impor tant safety advantages may not be realized.

Technology summary. Two important implications for technology integration merit further discussion. First it is clear that the informational con- 
tent, design, and for mat of the navigation technology will dictate the success of the technology. In all cases, changes to the content and interface could be envisioned that would either increase or decrease their effectiveness. As such, it is not sufficient to suggest that HUD technology will reduce navigation errors without empirical evaluations of the symbology and its effect on pilot workload, situation awareness, communication, and procedures. Second, when pilots made errors while taxiing with the technologies (i.e., datalink, and less frequently the EMM), they occurred most often when the captain was taxiing without the support of the FO. This warrants the important reminder that technology itself is not a panacea. Any technology must be car efully integrated into the cockpit along with a set of trained and practiced procedures. The technology will add little value to surface operations if procedures are not implemented in parallel to ensure effective use and communication of the information displayed.

\section{Generalizing Findings to the Operational Setting}

The findings and conclusions presented here were generated from observations of two high-fidelity simulations. It is important to acknowledge issues that may affect the generalizability of these findings. Specifically, the focus of this analysis was solely to understand pilot deviations and pilot-initiated navigation errors. The ground controllers in the simulation studies were confederates who were extensively trained and provided scripted communications that eliminated the possibility of ATC error. If anything, this likely reduced the frequency of errors both by eliminating ATC source errors, and reducing the number of communication misunderstandings between pilots and ATC. Also, the experiments simulated commercial, two-person crew aircraft operations. It is likely that a general aviation aircraft pilot who is solely responsible for maneuvering the aircraft, navigating, and communicating with ATC may experience different navigation problems and likely higher navigation rates. Finally, the two simulations tested arrival taxi sequences only, as these arrival taxi scenarios often place the pilot under higher workload conditions. Factors associated with exiting the runway safely and efficiently while receiving a taxi clearance clearly impact navigation errors. On the other hand, departure taxi operations may also produce a different pattern of navigation errors that were not uncovered in these simulations.

Nonetheless, it is expected that the relative frequency of planning, decision, and execution errors mirror closely that of real-wor ld oper ations. In fact, in a recent report, Boucek (2002) analyzed accident and incident data collected from the Aviation Safety Reporting System (ASRS) and categorized errors using the same error taxonomy presented here (or iginally presented in Hooey 
$\&$ Foyle, 2001). Of the 174 ASRS reports attributed to pilot error, 142 were classified as a planning error, decision error, or execution error. The results of the ASRS analysis revealed a very similar distribution of errors as observed in the simulation data with $32 \%$ planning errors, $37 \%$ decision errors, and $31 \%$ execution errors. (The study reported here found $23 \%, 42 \%$, and $35 \%$, respectively). Boucek's analysis of actual operations also revealed a four th class of error that was not observed in the simulation. Thirty-two additional reports were classified as violations of clearances in which the flight crew failed to follow procedure.

Despite the encour aging similarity of our simulation data to the real-world ASRS report data, it is still unclear how the over all error rate in the simulation mirrors the operational error rate. In fact the actual oper ational error rate remains unknown. The types of navigation errors, as observed in the simulations, are very rarely reported in the oper ational setting. In fact, even in the simulations some of the errors were not even detected by the pilots themselves. Clearly, benign navigation er ror soccur in the real world and frequently go unreported unless they lead to serious safety threats or runway incursions. The ASRS-repor ted errors ther efore represent only the very tip of the iceberg. Also, it is expected that the magnitude and relative frequency of errors within each error class will vary somewhat by air port. For example, air por ts with complex geometry may exhibit greater execution errors, whereas busier air por ts with a high degree of frequency congestion may experience a higher proportion of planning errors as a result of more frequent miscommunications. Further operational research is warranted to deter mine the magnitude of the navigation problem in the real world. To do this, it will be necessary to develop and institute a standard method of investigating and analyzing the human factors aspects of pilot deviations to fur ther our under standing of the root causes of these navigation errors. The FAA's intention to improve runway safety data collection, analysis, and dissemination (FAA, 2002b) will be an important step in this process.

\section{CONCLUSIONS}

The development of the taxi error taxonomy and post-hoc analysis of two full-mission simulations has greatly enhanced our understanding of procedural, operational, and environmental factors that contribute to pilot error. It is clear that navigation errors are not random events; rather they are fostered by limitations and constraints of the operational environment. This analysis revealed three categories of taxi navigation errors and suggests both procedural solutions and advanced cockpit technologies that can be used to augment pilots' cognition, decision making, and perceptual abilities, 
resulting in fewer navigation errors and increased surface operations safety.

\section{ACKNOWLEDGMENTS}

The development of the T-NASA prototype displays was funded by NASA's Terminal Area Productivity program and funding for this article was provided by the NASA Airspace Systems (AS)/Airspace Operations Systems (AOS)/Human Measures and Performance (HMP)/Human Automation Design Methods and Tools (HADMT) program. Portions of this article were previously presented at the 11th International Symposium on Aviation Psychology (see Hooey \& Foyle, 2001).

We acknowledge the significant contributions of Anthony Andre (San Jose State Univer sity) and Robert McCann (NASA Ames Research Center). Both were key contributors to the design of the T-NASA system and the empirical evaluations and error analyses reported herein. We also extend our thanks to all members of the error analysis team, most notably Bonny Parke (San Jose State University) and Dan Renfroe. We also extend appreciation to the McCulloch Group for their statistical advice and expertise in conducting the Bayesian statistical analyses.

\section{REFERENCES}

Adam, G. L., \& Kelley, D. R. (1996). Reports by airline pilots on airport surface operations: Part 2. Identified problems and proposed solutions for surface operational procedures and factors affecting pilot performance (MITRE Tech. Rep. No. MTR94W0000060.v2). McLean, VA: MITRE.

Andre, A. D. (1995). Information requirements for low-visibility taxi oper ations: What pilots say. In R. S. J ensen \& L. A. Rakovan (Eds.), Proceedings of the 8th International Symposium on Aviation Psychology (pp. 484-488). Columbus: Ohio State University.

Boucek, G. P. (2002). Surface accident and incident taxonomy and mitigation strategies (Tech. Rep. No. RTI/8348/003-01S). Research Triangle Park, NC: Center for Aerospace Technology, RTI International.

Feder al Aviation Administration. (2001). Advisory circular 120-74: Procedures during taxi operations. Washington, DC: Author.

Federal Aviation Administration. (2002a). FAA runway safety report: Runway incursion trends at towered airports in the United States 1998-2001. Washington, DC: Author.

Federal Aviation Administration. (2002b). Runway safety blueprint 2002-2004. Washington, DC: Author.

Federal Aviation Administration Safe Flight 21. (2002). Safe flight 21 master plan 3.0. McLean, VA: MITRE.

Foyle, D. C., Andre, A. D., McCann, R. S., Wenzel, E., Begault, D., \& Battiste, V. (1996). Taxiway navigation and situation awareness (T-NASA) system: Problem, design, philosophy, and description of an integrated display suite for low visibility air port surface oper ations. SAE Transactions: Journal of Aerospace, 105, 1411-1418. 
Foyle, D. C., Hooey, B. L., Wilson, J . R., \& Johnson, W. A. (2002). HUD symbology for surface operations: Command guidance vs. situation guidance formats. SAE Transactions: Journal of Aerospace, 111, 657-658.

Foyle, D. C., McCann, R. S., \& Shelden, S. G. (1995). Attentional issues with superimposed symbology: Formats for scene-linked displays. In R. S. Jensen \& L. A. Rakovan (Eds.), Proceedings of the 8th International Symposium on Aviation Psychology (pp. 98-103). Columbus: Ohio State Univer sity.

Gelman, A., Carlin, J. B., Stern, H. S., \& Rubin, D. B. (1995). Bayesian data analysis. London: Chapman \& Hall.

Hooey, B. L., \& Foyle, D. C. (2001). A post-hoc analysis of navigation er or s during surface operations: Identification of contributing factors and mitigating strategies. In R. S. Jensen, L. Chang, \& K. Singleton (Eds.), Proceedings of the 11th Symposium on Aviation Psychology. Columbus: Ohio State Univer sity.

Hooey, B. L., Foyle, D. C., \& Andre, A. D. (in press). The design of aircraft cockpit displays for low-visibility taxi operations. Vision in vehicles 9.

Hooey, B. L., Foyle, D. C., Andre, A. D., \& Parke, B (2000). Integrating datalink and cockpit display technologies into current and future taxi oper ations. In Proceedings of IEEE/AIAA Digital Avionics Systems Conference (pp. 7.D.2-1-7.D.2-8). Piscataway, NJ : IEEE.

Hooey, B. L., Schwirzke, M. F. J., McCauley, M. E., Renfroe, D., Purcell, K., \& Andre, A. D. (1999). Issues in the procedural implementation of low-visibility landing and surface operation displays. In R. S. Jensen, B. Cox, J. D. Callister, \& R. Lavis (Eds.), Proceedings of the 10th Symposium on Aviation Psychology (Vol. 2, pp. 797-803). Columbus: Ohio State Univer sity.

Kerns, K. (1990). Data link communication between controllers and pilots: A review and synthesis of the simulation literature (Tech. Rep. No. MP-90W00027). McLean, VA: MITRE.

Lasswell, J. W., \& Wickens, C. D. (1995). The effects of display location and dimensionality on taxi-waynavigation (Tech. Rep. No. ARL-95-5/NASA-95-2). Savoy: Univer sity of Illinois Aviation Research Laboratory.

McCann, R., Foyle, D. C., Hooey, B. L., \& Andre, A. D. (1999, April). Pilot interactions with an electronic display suite to support low-visibility taxi. In Countering the Directed Energy Threat: Are Closed Cockpits the Ultimate Answer? Panel at the Third Symposium of the Human Factors $\&$ Medicine Panel. NATO. Antalya, Turkey.

McCann, R. S., Hooey, B. L., Parke, B., Foyle, D. C., Andre, A. D., \& Kanki, B. (1998). An evaluation of the Taxiway Navigation and Situation Awareness (T-NASA) system, in high-fidelity simulation. SAE Transactions: Journal of Aerospace, 107, 1612-1625.

Parke, B., Kanki, B., McCann, R. S., \& Hooey, B. L. (1999). The effects of advanced navigation aids on crew roles and communication in ground taxi. In R. S. Jensen, B. Cox, J. D. Callister, \& R. Lavis (Eds.), Proceedings of the 10th International Symposium on Aviation Psychology (pp. 804-809). Columbus: Ohio State Univer sity.

Parke, B., Kanki, B. G., Munro, P. A., Patankar, K., Renfroe, D. F., Hooey, B. L., et al. (2001). The effects of advanced navigation aids and different ATC environments on task-management and communication in low visibility landing and taxi. In R. S. Jensen, L. Chang, \& K. Singleton (Eds.), Proceedings of the 11th International Symposium on Aviation Psychology. Columbus: Ohio State Univer sity.

Reason, J. (1990). Human error. New York: Cambridge University Press.

Thomas, A. (1994). BUGS: A statistical modelling package. RTA/BCS Modular Languages Newsletter, 2, 36-38.

\section{APPENDIX}


Both the more commonly used chi-square and frequentist logistic regression analyses were considered and ruled out in favor of the Bayesian analysis. The chi-square method suffers from two limitations that are particularly relevant for the data set. First, the chi-square distribution assumption, which is necessary for hypothesis testing, breaks down when the number of counts in any cell of the contingency table is very small. We observe this condition throughout our data due to the large number of no-error trials. Second, chi-square independence tests can give misleading results when applied to data derived from multiway contingency tables as we have in this situation. To perform a chi-square test one must collapse (marginalize) the multiway table down to a two-dimensional table for each margin of interest. This marginalization can either reduce statistical power or over state effect sizes, depending on the behavior of the margins over which one has collapsed. The logistic regression is well-suited to multiway contingency tables. However, the resulting likelihood functions turn out to be severely skewed due to the high number of no-error trials. A frequentist analysis of the logistic regression must then be considered suspect because of the nonnormality of the resulting sampling distributions of the maximum likelihood estimators. Applying a frequentist logistic regression to these data would result in overly conservative probability values. We prefer the Bayesian analysis of the logistic regression because it provides the same framework for multiway contingency tables but does not rely on any assumptions of normality (see Gelman, Carlin, Stern, \& Rubin, 1995).

Manuscript First Received: July 2003 